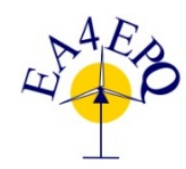

International Conference on Renewable Energies and Power Quality (ICREPQ'14) Cordoba (Spain), $8^{\text {th }}$ to $10^{\text {th }}$ April, 2014

Renewable Energy and Pourer Quality. Fournal (RE\&PQJ)

ISSN 2172-038 X, No.12, April 2014

\title{
Reduction of Losses in the Conductors of a Sustainable Street Lighting as a Technique for Managing Energy Consumption and $\mathrm{CO}_{2}$ Emissions
}

\author{
J.A. Lobão ${ }^{1}$, T. Devezas ${ }^{2}$ and J.P.S. Catalão ${ }^{2,3,4}$ \\ ${ }^{1}$ Polytechnic of Guarda \\ Av. Dr. Francisco Sá Carneiro 50, 6300-559 Guarda (Portugal) \\ Phone: +351271220 111, Fax: +351271220690 \\ e-mail: jlobao@ipg.pt \\ ${ }^{2}$ University of Beira Interior \\ R. Fonte do Lameiro, 6200-001 Covilhã (Portugal) \\ Phone: +351 275329 914, Fax: +351275329 972 \\ e-mail: tessalen@ubi.pt; catalao@ubi.pt \\ ${ }^{3}$ INESC-ID, R. Alves Redol, 9, 1000-029 Lisbon, Portugal \\ ${ }^{4}$ IST, University of Lisbon, Av. Rovisco Pais, 1, 1049-001 Lisbon, Portugal
}

\begin{abstract}
In recent years there has been a series of documents such as the European Strategy 20-20-20 to address the issue of energy efficiency in various sectors of activity. Your objective is to reduce $20 \%$ of energy consumption, $20 \%$ of GHG emissions (Greenhouse Gases) and get $20 \%$ of the energy consumed is from renewable sources [1]. The reduction of losses in the conductors of a sustainable street lighting installation as a technique for managing energy consumption, also allows the reduction of emissions of greenhouse gases, accounted for in this paper. Reduction of losses in the conductors of a sustainable street lighting, allowing a better use of the installed power, which can be an important issue, particularly allows increasing the weight of the renewable energies.
\end{abstract}

\section{Key words}

Street lighting, greenhouse gases, sustainable energy, efficiency lighting, losses

\section{Introduction}

The electricity sector is responsible for a large portion of greenhouse gases, directly in the act of generating electricity, especially in thermoelectric plants from fossil fuels and indirectly in the extraction, transportation and processing of fuels and raw materials used in the plants producers of electricity from thermoelectric to renewable energy.
If, on the one hand, the production of electricity releases greenhouse gases into the atmosphere contributing to climate change, on the other hand, climate change influence the production of electricity in particular use and planning new power generation plants based on the implications of these changes.

In this complex relation and interconnection of influences, various studies have been developed. The influence of climate change on energy production, has been the subject of study in various sources, in particular renewable energies. More vulnerable due to its dependence on weather and climate.

Impact of climate change in general about wind power [2], in specific regions such as the analysis of the impacts of climate change on gross output hydropower in Europe [3].

This study presents a new software application compares and chooses the best investment and experimental validation in the solutions of installations of street lighting. The choice of efficient street lighting is related to the following factors: price, power consumption, reduction of losses in the conductors, useful life, and interest rate. The losses in the conductors will be analyzed based on the current which passes throughout the street lighting installation. The analysis allows various possibilities, allowing you to choose the analysis of a specific individual point of light, replace the existing technology on a street or in a selected group of streets or 
make replacement or control all luminaires installed simultaneously; investment analyses and advises more efficient. The $\mathrm{CO}_{2}$ reduction is calculated using conversion factors of the regulations for the electrical energy.

\section{Development}

\section{A. Identification of the Parameters}

\section{Physical parameters:}

Knot Connection (CK);

Connections between knot Connection;

Length of branch conductors in knot

Connection;

Section of branch conductors in knot

Connection;

\section{Load parameters:}

Power of the loads connected to the electrical installation;

Efficiency of the loads;

Power factor of the loads;

Daily load diagram;

Daily load diagram of the lamps and system control for economic analysis.

\section{Operating parameters:}

Operating time of the street lighting installation; Monthly operating days (d);

Months of annual operation (m);

Cost of electricity $(€)$;

Interest rate

\section{B. Installation Characteristics}

Figure 1 shows a typical installation with the respective parameters.

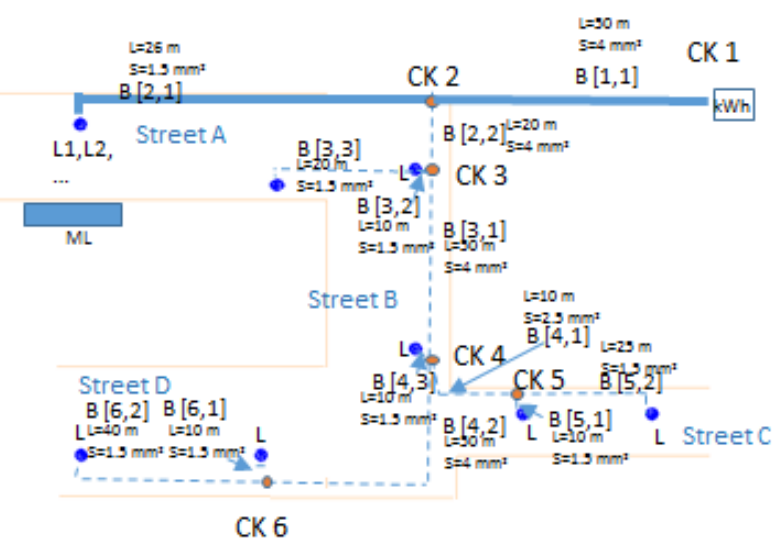

Fig. 1. Scheme of an installation.

\section{Calculations}

After inputting the parameters and load diagrams, the following calculations are made:
- Determination of the load diagram associated to the branch knot Connection, adding the corresponding load diagrams.

Example: the branch "2" in "CK2" is the sum of branch diagrams in "CK3".

- The currents in all conductors of the electrical installation due to:

-Initial load diagram $\left(\mathrm{I}_{1}\right)$

-Load diagram of lamps efficient $\left(\mathrm{I}_{2}\right)$.

- Difference in cable losses $(\Delta \mathrm{P})$ in the conductors affected by the changed equipment (identified in bold in Fig.1).

$\Delta \mathrm{P}=\mathrm{R}\left(\mathrm{I}_{1}\right)^{2}-\mathrm{R}\left(\mathrm{I}_{2}\right)^{2}$

- $\quad$ Profits from the variation of cable losses (G1).

$(\mathrm{G} 1)=\Delta \mathrm{P} * \mathrm{~d} * \mathrm{~m} * €$

- Profits from the variation of power equipment (G2).

$(\mathrm{G} 2)=(\mathrm{P} 1-\mathrm{P} 2) * \mathrm{~d} * \mathrm{~m} * €$

- Total profits.

$\mathrm{R}=(\mathrm{G} 1)+(\mathrm{G} 2)$

- Reduction of $\mathrm{CO}_{2}$

$\Delta \mathrm{CO}_{2}=[\Delta \mathrm{P}+(\mathrm{P} 1-\mathrm{P} 2)]^{*} \mathrm{~d}^{*} \mathrm{~m} * 0.47$

\section{Economic Evaluation}

In this work, the VAL (net present value) or Payback Period (PP), is used, which is computed from the sum of the annual cash-flows for a given annual interest rate.

The payback period (PP), for the investment can be calculated using the following equation [4]:

$P P=\ln \frac{100 W_{e l} C_{e}}{100 W_{e l} C_{e}-i C_{i n v}}-\ln \frac{100+i}{100}$

with:

Wel- Electricity savings Ce- Electricity cost WelCe- Net profit Cinv - New investment i - Annual interest rate

The VAL (net present value), for the investment can be calculated using the following equation [7]:

The interest rate is indicated by the investor according to the desired profitability.

$$
V A L=\sum_{k=0}^{n} \frac{T_{p}-D_{k}-I_{k}}{(1+i)^{k}}+\frac{V}{(1+i)^{n}}
$$

with:

Tp - Total profit

D - Operation cost 
I - New investment

$\mathrm{n}$ - Years of useful life

$\mathrm{V}$ - Residual value for the old equipment

i - Annual interest rate

\section{Results}

The load diagrams are shown in Figures 2 to 4 .

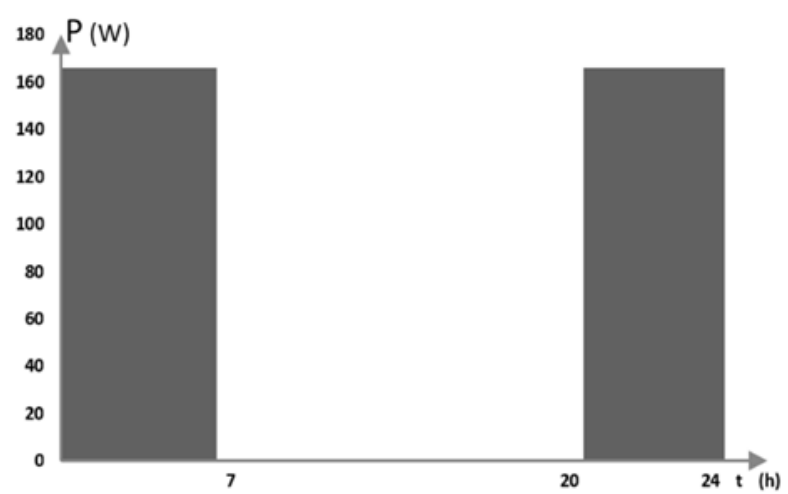

Fig. 2. Load diagram initial (all the streets)

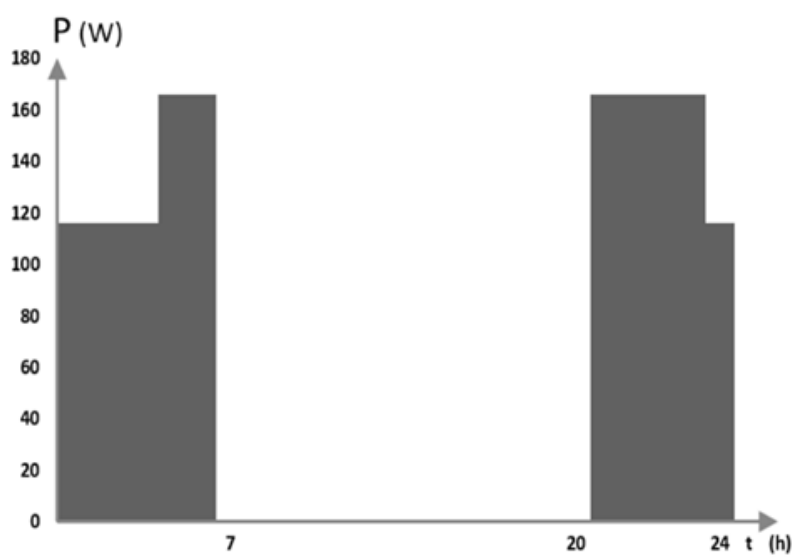

Fig. 3. Load diagram using bi-power ballasts

(Lamp 1 in the streets D)

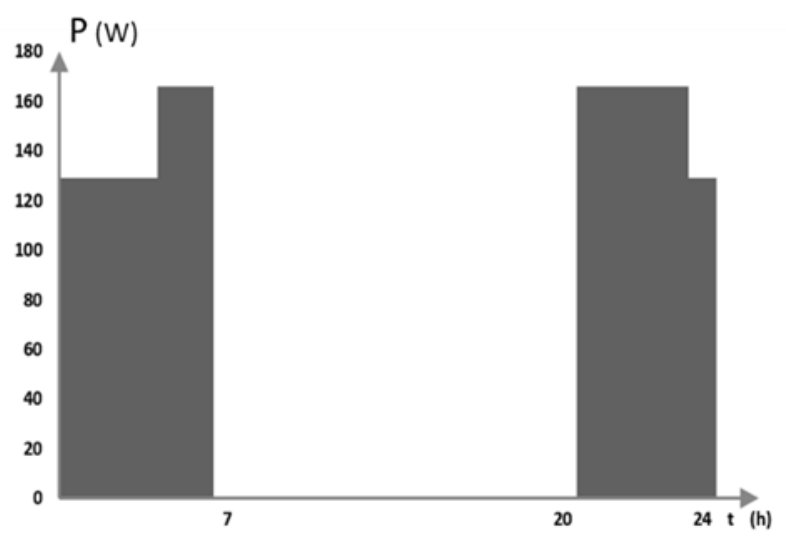

Fig. 4. Load diagram using bi-power ballasts

(Lamp 2 in the streets D)
Figure 5 presents the results of the software application to the results compare an initial situation with luminaires of $166 \mathrm{~W}$ (Load diagram fig.2) with other when using bipower ballasts $116 \mathrm{~W}$ (Load diagram fig.3) with investment of $39 €[4]$ and with other when using bipower ballasts $129 \mathrm{~W}$ (Load diagram fig.4) with investment of $30 €$ in the street D of the Fig. 1 .

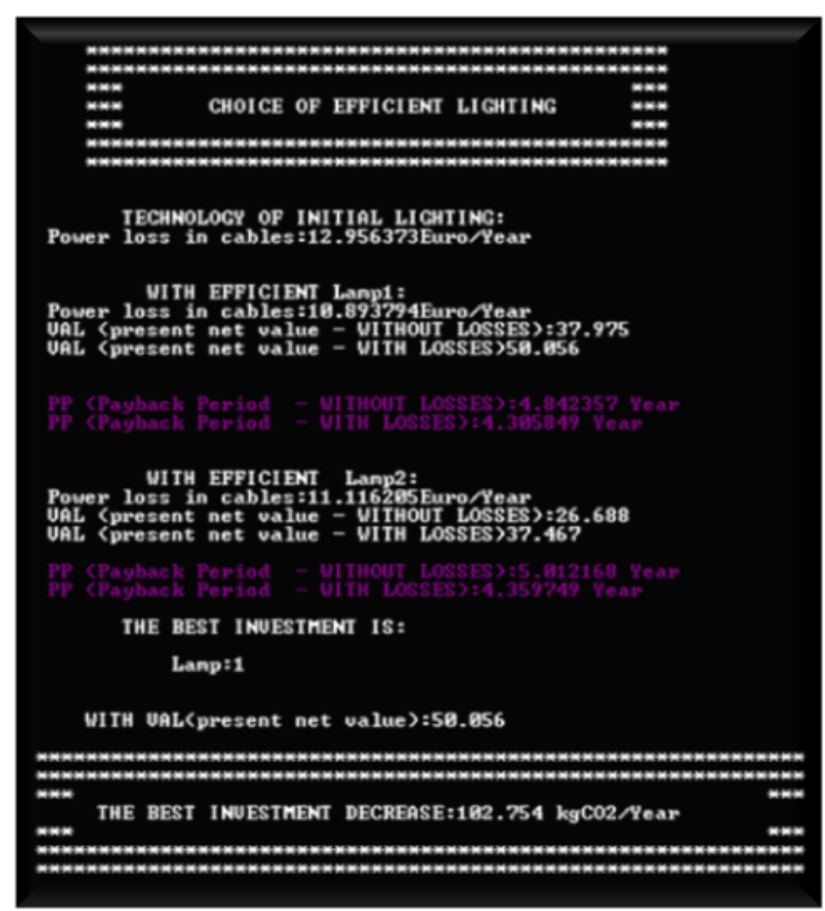

Fig. 5. Results of the overall output of the simulation

The experimental setup can be seen in Fig. 6 for which the scheme is provided in Fig. 1, verifying experimentally the simulation results

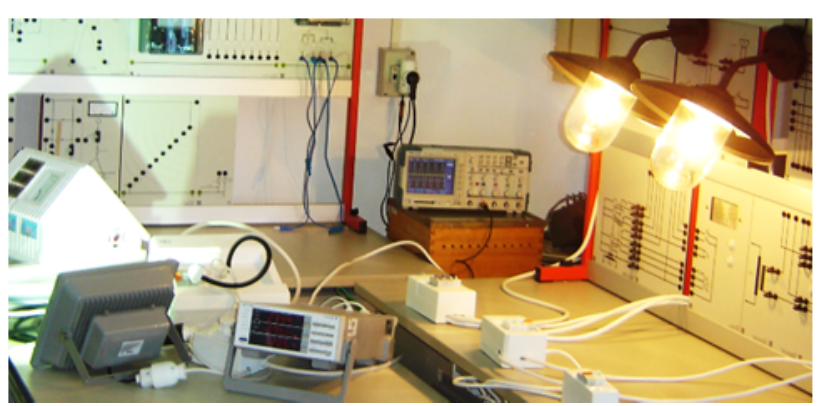

Fig. 6. Experimental setup.

\section{Conclusions}

The work presented a software support in choosing luminaires and control systems for street lighting installations, in cases of new or remodeled projects, or an individual spotlight. It can be concluded that losses in street lighting installations, although small, are not null and can make a considerable difference in the economic evaluation. Reducing the consumption, increases the weight of the renewable energies and reduces the $\mathrm{CO}_{2}$ emitted into the atmosphere. The sum of all those small contributions shall provide great help in reducing overall greenhouse gas emissions. 


\section{Acknowledgment}

This work was supported by FEDER funds (European Union) through COMPETE and by Portuguese funds through FCT, under Projects FCOMP-01-0124-FEDER020282 (Ref. PTDC/EEA-EEL/118519/2010), PEstOE/EEI/LA0021/2013 and PEst-OE/EGE/UI4056/2014 UDI/IPG. Also, the research leading to these results has received funding from the EU 7th Framework Programme FP7/2007-2013 under grant agreement no. 309048.

\section{References}

[1] N. Jollands, P. Waide, M. Ellis. The 25 IEA energy efficiency policy recommendations to the G8 Gleneagles Plan of Action. Energy Policy; 38 (2010) 6409-6418.
[2] S.C. Pryor, R.J. Barthelmie. Climate change impacts on wind energy: a review. Renewable and Sustainable Energy Reviews, 2010; 14: 430-437.

[3] A.B. Lehner, G. Czisch, S. Vassolo. The impact of global change on the hydropower potential of Europe: a model-based analysis. Energy Policy, 2005; 33: 839-855.

[4] M. Kostic, L. Djokic. Recommendations for energy efficient and visually acceptable street lighting. Energy, 34 (2009) 1565-1572.

[5] Allison N. Sperber, Andrew Curtis Elmore, Mariesa L. Crow, Jeffrey D. Performance evaluation of energy efficient lighting associated with renewable energy applications. Renewable Energy; 44 (2012) 423430. 